\title{
Analysis of the Alienation of Education from the Perspective of New Era
}

\author{
Jing Zhou, Qingwei Chao \\ Xi'an University of Science and Technology \\ Shaanxi, Xi'an, 710054
}

\begin{abstract}
With the rapid development of China's education industry, alienation phenomenon of paying too much attention to wealth value creation has appeared in the field of education since reform and opening up. From the perspective of the new era, this paper analyzes four aspects: the alienation of educational value orientation, the alienation of educational content, the alienation of educational evaluation, and the alienation of educational methods and proposes the corresponding solutions which are of great significance to promote the healthy development of education business and realize the social harmony.
\end{abstract}

Keywords-New era; Education alienation; Countermeasures

\section{INTRODUCTION}

The report of the 19th National Congress of the Communist Party of China pointed out that socialism with Chinese characteristics has entered a new era after a long and arduous effort. "The main contradiction of our society has been transformed into the contradiction between the people's increasing demand for good life and the unbalanced and insufficient development." [1] This means that with the continuous development of society and the continuous enrichment of material resources, the main contradiction of education in the new era has gradually evolved into the contradiction between the people's increasing demand for high quality education and the unbalanced and insufficient supply of educational resources and environment and so on since the reform and opening up. The report pointed out that "building a powerful education country is the foundation work of the great rejuvenation of the Chinese nation, so we must put education business in priority position, speed up the modernization of education, and do a good job of the education satisfying the people." [2] At present, our country's education business is facing some difficult problems needed to be solved. The problem of education alienation is one of them. It is of great significance to study and solve this problem from the perspective of new era.

\section{OVERVIEW OF THE PROBLEM OF EDUCATION ALIENATION}

The word "alienation" originated from Latin (alienation), which has the meaning of alienation, disengagement and so on. In the German classical philosophy, the meaning of the word is "when the subject developed to a certain historical stage, it can split out its opposite and become an external dissident force." [3] Marx gave the meaning to "Eettvemdnng" that:" it is used to express exchange activities, transforming from one state to another, that is, to represent the economic and social phenomena that do not imply the relationship between hostility and dissident nature." [4] Based on the understanding of the concept of "alienation", "education alienation" is the inevitable outcome of the development of social history to a certain stage. Its appearance is not accidental, but a social and historical necessity. "Education alienation means that in the field of education, education itself has lost its own meaning as the means of people cultivating the next generation of people to make them better transform nature and society, but in turn, it has manipulated the next generation of people, making people's development become the means to achieve educational purposes, making people lose their original features, manipulated by education and alienated by education." [5] Exploring the problem of education alienation in the new era is of far-reaching significance for the development of education at this stage and afterwards.

The education alienation is no longer a general definition of the alienation of people and education only from the simple literal sense. Education alienation is mainly characterized by the hierarchization of education, the bureaucracy of education, the quantification of education and the generality of education. The education alienation appears because the alienation of science and technology, becoming the external force to dominate people [6]. The education alienation can be divided into the alienation of educational function, the alienation of educational policy and the alienation of educational people from the medicine feeding event happened in the kindergarten and attracted a lot of attentions from society [7]. From the existing relevant research results, you can see that the problem of education alienation in our country has reached a very serious degree, students' practical ability and innovation ability are relatively low, and the problem of people having high scores but low ability is becoming more and more serious. With the gap between urban and rural development in China, the gap between the development of first-tier cities and the development of other cities, the education alienation has aggravated the seriousness of the disequilibrium of educational resources. The concept that "officialdom is the natural outlet for good scholars" is deeply rooted in the hearts of the people, making the reform of education more difficult. 


\section{CURRENT SITUATION OF EDUCATION ALIENATION IN CHINA AND ITS REASONS}

\section{A. Current situation of the problem of education alienation in China}

Firstly, the alienation of educational value orientation. With the development of the times, education has gradually lost its original pattern under the impetus of economic benefits. Under utilitarianism, the most primitive concept to educate people for cultivating moral integrity has gradually evolved into taking education as a means for a living. The essence of education is a kind of inheritance of experience under the demand of the times. It is a process of cultivating the people to develop in all directions, but also a complex process of promoting the comprehensive quality of the educatees according to educators' own experience knowledge, thus educating the talents who can adapt and promote the development of the society. However, this definition has gradually changed in the development of history, especially in the situation of emphasizing the economic benefits and practical values in the development of modern society, education is more and more engulfed by commercialization, industrialization and marketization, and it has been more added with the additional terms of political value and economic benefit, so that the cultivated people are no longer creative talents who pursue comprehensive development and would promote social development, but become social development tools only pursuing wealth value.

Secondly, the alienation of educational content and educational methods. In recent years, in the pressure of entering a higher school, the "excessive assignments tactic", "Mathematical Olympiad" and other education models have been constantly emerging. From some aspects, the two-way interaction of teaching has become more unidirectional and passive, the students are overburdened. The mode that the more difficult the pursuit is, the better the students are aroused makes teaching deviate from the purpose, blindly pursuing for difficulty rather than the complete digestion of students. However, the students' after-school time for improving their personalized development is also occupied by various tutoring classes and continuation classes. The learning and living modes of "three points in a line" every day makes the students learn more mechanically from the other level. The teaching content is not adjusted and reformed correspondingly in time with the change of social life, it cannot achieve the teaching purpose of stimulating the students' creativity and free development. With the Chinese nation developing to today, history and culture are constantly replaced and overlapped, and science and technology are developing rapidly at an unprecedented rate. However, our educational methods are mainly based on cramming education, and students can only play the role of the recipients in this unidirectional and compulsory education process, and teachers cannot get the interactive feedback as the grantor in this process because of this unidirectional education model. Teachers gradually get numb, teach for teaching, and become the passive persons relative to the teaching task in this process. Teachers and students have lost the initiative in the course of teaching instead of giving full play to autonomy, spontaneity and creativity. In the end, education will lose its original vitality once again. We have been pursuing "peopleoriented" and emphasizing the dominant position of human beings in society. However, this cramming education just deviates from our spirit of times.

Finally, the alienation of educational evaluation. The alienation of educational evaluation mainly reflected in the way of evaluation, the standard of evaluation and the subject of evaluation, etc. At present, the evaluation method for students at school is still examination oriented, and students have changed from learning subjects to "examination machines". Correspondingly, the single assessment system of test scores restricts the multidimensional development of students. Although scores can be used to measure students' mastery of textbook knowledge, they cannot measure other skills except for academic record. Moreover, as the educated subjects, students should be the subjects of education evaluation, but at the present stage, students play a more passive role in evaluation. Most of the subjects of evaluation are educators rather than the educated persons. This makes the important link of teaching evaluation separated from the basic relevance with the students, which is not only unfavorable to the effective reform of education and teaching, but also unfavorable to the cultivation of students' independent consciousness and personal growth.

\section{B. Reasons for education alienation at the current stage of our country}

The problem of education alienation is a part of the whole social system. It is not isolated, but plays a vital role in the development of society. Its emergency is influenced by multiple factors, such as the society, politics, economy and culture and people themselves, etc.. The education alienation is accompanied by the social production and life. The level of productivity development, the educational system and the influence of values are the social roots of education alienation.

First of all, social, political, economic and cultural backwardness is the basic reason for the education alienation. Marx's theory of three major social forms believes that the development of human history is divided into three stages: "dependence of human beings", "dependence of things" and "free, personalized and all-round development of human beings". "The dependence of things" is a form in the current historical period of the society, which is mainly characterized by the independence of human beings based on the dependence of things. "In this form, it is possible to form universal social material exchange and comprehensive relations and system with multidimensional needs and comprehensive abilities." [8] Due to the influence of the material conditions, educators and educated persons have to obtain more material wealth through certain social labor in the process of education to meet the material needs of all aspects. For historical factors, the proportion of people receiving higher education in China is too low in the past, making material wealth become the goal of most people to strive for. In the process of social development, education has become a way to break class solidification. At this stage, people cannot really realize the true meaning of education, so they learn in order to pursue material wealth. This phenomenon has become their educational purpose, resulting in the utilitarianism and commercialization of education, and the educated persons only learn for the exam results. Fame and wealth have become the purposes of the 
educators and the educated persons, which are contrary to the original intention of education, and education has begun to alienate.

Secondly, the unsound educational system is the artificial factor for the emergence of education alienation. The development direction of education is greatly influenced by the guidance of the educational system. If the educational system is unsound and the educational system is not perfect, it will directly affect the development of education, which leads to the emergence of education alienation. With the rapid development of the city and the relatively backward situation in the rural areas, more and more parents are willing to send their children to the cities with relatively good educational resources and environment. In order to prevent the excessive concentration of urban population which will produce a series of situations which impede the development of the city appear. The fairness of education is seriously affected by taking regional registered permanent residence as restriction, taking the level of academic degree as the standard of judging the working ability, and such educational system taking the result as the standard of judging the students' learning makes education deviate from its true pursuit. When the educated persons are mastered by the academic diplomas and exam results and controlled by the regulations of regional household register and others, they will gradually loss their critical thinking abilities again on the basis of being unable to enjoy the equal education resources, and cannot achieve their own comprehensive free development. The process from the beginning of accepting the education to entering the society to work is regarded as the process of being connected. In this sense, people are competing to choose "good kindergartens" and "good primary schools", making the famous school become a "plot". The defects of the system result in the uneven distribution of educational resources.

Finally, alienation of values is the catalyst for education alienation. In the long history of 5000 years of traditional culture in China, the academic essence of hundred schools of thought has influenced generations of Chinese people and trained many talented people. Since 1980s, Western schools of thought have poured into our country. The open thought and fast food culture have deeply affected our life. In the process of cultural blending and inheritance, some of our traditional cultures have been impacted. People have become confused in the alternation of Chinese and Western cultures and the tide of market economy further impacts on the traditional culture based social traditional civilization and spirit, plus people's desire for money, making many people lose the direction and grovel at the foot of money. Wealth has become the sign of status, power and knowledge capability, which is the symbol and ideal of people's pursuit for success. The relationship between people is increasingly flooded with interest, and education becomes a means to pursue interests when the process of people's pursuit for wealth is misinterpreted as the satisfaction of material desires. Education is no longer to promote the comprehensive and free development of people, but practical and economic value is more regarded as the purpose of education.

\section{COUNTERMEASURES AGAINST THE PROBLEM OF} EDUCATION ALIENATION AT THE CURRENT STAGE OF CHINA

The education alienation is a historical phenomenon. It is the product of the social development to a certain stage. It will not suddenly appear or disappear in a short term. The emergence of education alienation has its special historical conditions. It will also gradually disappear with the continuous development of China's productive forces, like other social and historical phenomena.

First of all, the continuous emancipation and development of the productive forces constantly enrich the material life of the people. The key to solve education alienation lies in the development level of productivity. With the high development of the productive forces, people are less likely to be materialized and education is no longer a simple way to pursue fame and wealth, which is more conducive to the development of people's personality and creativity, thus promoting the free and comprehensive development of people. With the continuous development of society and the increasingly rich and balanced social resources, the degree of people being materialized has been greatly reduced, which will restore the original appearance of education. Therefore, the root to dissolve the education alienation lies in the development of productive forces.

Secondly, we should improve the educational system and optimize the educational environment. To improve the educational system, we can start from three aspects: firstly, it is necessary to accurately locate the role of the examination, and appropriately and reasonably use the evaluation means of exams. It is undesirable to make the exam become the standard to judge whether the result of education and teaching is good or bad, or use the single exam result as the only indicator to judge the students' study. But in the process of rational, moderate and correct use of exam, the defects of education and teaching can be found in time, so that exam can pay a role in chasing leaks and filling vacancy and become powerful support to improve and cultivate students. Secondly, we should form a two-way interactive teaching mode, relocate and adjust the relationship between teachers and students, so that teachers and students are free from the unidirectional teaching mode to achieve the full communication between the students and the teachers. Common progress makes teachers and students realize they all can get all-round development in this interactive process. Thirdly, we should improve the evaluation system of education and teaching, pay attention to the diversity of the evaluation subjects, and strive to bring the educated persons, educators, participants of educational activities and others into the subjects of education evaluation, which can improve the quality of education, obtain many aspects of information, and promote the teaching contents to be continuously improved and be fully developed. Besides, educational evaluation should pay more attention to the role of multiple evaluations and strengthen the supervision mechanism of evaluation.

Finally, "trinity" type linkage education is formed. Education is not only the responsibility of school, but also the result of the interaction of various links in the process of people's growth. Family education exerts a subtle influence on students' characters, and the initial formation and cultivation of 
values and cognition of the world are sprouting up here. School education is the most standardized education, and social education is a diversified mode of education. The education can be optimized only by realizing the "triangle education" of the family, the school and the society, and making the educated persons in the "center of gravity" of the triangle. This requires the three parties to play a linkage role under the neck-and-neck condition.

\section{CONCLUSION}

Eliminating the phenomenon of education alienation is a long-term task. We should further implement the spirit of the 19th National Congress of the Communist Party of China, vigorously develop the social productive forces, deepen the reform in the field of education in our country, run a satisfactory educational business, let every student enjoy a fair education with quality assured and gradually eliminate the phenomenon of education alienation, to achieve the goal of building a powerful country in education and promote the harmonious development of society.

\section{ACKNOWLEDGMENT}

Brief introduction of the author: Jing Zhou (1965- ), female, Jiangsu Changzhou people, Professor of Xi'an University of Science and Technology School of Marxism.

Qingwei Chao (1995- ), female, Shaanxi Baoji people, Postgraduate student of Xi'an University of Science and Technology School of Marxism.

Contact way: Room 1110, Office of Xi'an University of Science and Technology School of Marxism, No. 58, Yanta Road Middle Section, Xi'an City, Shaanxi Province.

Postal code: 710054

E-mail: 1043408831@qq.com; Tel: 18829348042 (02985583835)

\section{REFERENCES}

[1] Jinping Xi: Decisive Victory in Building a Well-off Society in an AllRound Way, Winning a Great Victory for Socialism with Chinese Characteristics in the New Era, from China Culture Daily, October 19, 2017.

[2] Jinping Xi: Decisive Victory in Building a Well-off Society in an AllRound Way, Winning a Great Victory for Socialism with Chinese Characteristics in the New Era, from China Culture Daily, October 19, 2017.

[3] Hagel: Philosophy of Mind, the third part of Encyclopedia of Philosophy, People's Publishing House, February, 2006.

[4] Selections of K. Marx and F. Engels (Volume 1) [M]. Beijing: People's Publishing House, 2012:874.

[5] Zuofang Wan. Education Alienation: Concept and Performance [J]. Journal of Fujian Normal University, March, 2003.

[6] Jiajun. Zhang Discussion on Alienation and Sublation of Education [J]. Theory and Practice Education, October, 2008.

[7] Qiaoying Wang. Discussion on Alienation of Education - from Talking about "Medicine Feeding in Kindergarten" [J]. The Guide of Science \& Education, April, 2015.

[8] Karl Marx and Frederick Engels Volume 46 [M]. Beijing: People's Publishing House, 1979:104. 